\title{
Building Energy System Design and Planning: The Universidad de Santander Case
}

\author{
I.D. Serna-Suárez ${ }^{1, *}$, A. Martínez-Gonzalez ${ }^{2}$, S. Urbano-Contreras ${ }^{3}$ \\ ${ }^{1}$ Universidad de Santander \\ ${ }^{2}$ Facultad de Ingenierías \\ Santander, Colombia \\ *corresponding author: coordinador.msea@udes.edu.co
}

Article Info

Received:

15 March 2021

Accepted:

25 May 2021

Published:

1 June 2021

DOI:

https://doi.org/10.14710/j

sp.2021.11202

\begin{abstract}
Renewable generation is gaining more thrust as the time passes, however, the growth rate of such production has been faster than the rate of the electrical grid modernization. This growth comes with great opportunities and challenges for building energy system (BES) design and planning. In this respect, this paper presents the experience and lessons learned from the design and planning of the BES of the "Universidad de Santander" (UDES) central campus. This BES renewable generation is composed of a rooftop PV system distributed across the campus buildings. The system started with $30 \mathrm{kWp}$ of installed capacity (100 kWh/day on average) and now is ready to deliver near $300 \mathrm{kWh} /$ day thanks to $70 \mathrm{kWp}$ of extra capacity installed. In general, the implementation has been a success that now is being replied in other UDES' campuses, and the decision taking involved highlighted the importance of a proper energy efficiency policy and electrical regulation analysis.
\end{abstract}

\section{Keyword:}

Power markets, DER system design, energy management systems, operation and control of power systems.

\section{Introduction}

The concept of city is a fundamental idea in modern life since it promotes the financial cost-efficiency, of course, at the expense of other aspects -e.g., sustainability. At the core of modern cities or cities with reduced space are high rise buildings, a type of construction characterized by a very high energy consumption density. As a consequence, buildings in developed countries consume around $40 \%$ of the primary energy input [1]. One can argue that this might not apply to developing countries. However, due to the immature production and manufacture sector of some of these countries, residential and commercial building energy consumption can be even twice as large as the industrial energy demand. As a consequence, the promotion of an energy-efficient building design approach and the 
transitioning towards a more sustainable construction sector can lead to significant energy efficiency savings [2].

Some regulations and business models have appeared in the last decades to incentivize the transition towards a more sustainable society. For example, from the technological point of view, there is the "Maximise material and energy efficiency" and "Create value from waste" approaches; from the social point of view some business and regulations are focused on the "Encourage sufficiency" aspect; and from the organizational point of view, the goal is to "Develop scale-up solutions" [3]. Despite these efforts, the building design and construction still have not been massified, and, in contrast, the inclusion of renewable energy from non-conventional sources (e.g., sunlight and wind) is strading its way through every country in the globe.

For sure, the integration of renewable energy is a crucial component towards achieving sustainability; however, when wrongly executed in the building sector can be counterproductive. As presented in [4], renewable energy by itself has a very narrow scope when applied to sustainable building design. Still, when combined with digital technologies, it can leverage the benefits and, thus, its integration. But, even with the right combination of technology and benefits, some applications can be ignored because of the lack of awareness, education, and qualified professionals [5]. Indeed, the barriers and opportunities that are faced in the field of building efficiency are quite complex, and thus, the subject of study of many researches. This paper main objective is to serve as a start point to study the guidelines on the barriers and opportunities to take into account when designing a sustainable building. Additionaly, it is presented the Universidad de Santander experience on the integration of a PV roof in the main campus.

This paper is organized as follows: In section 5, the guidelines are presented based on international experiences and surveys found in the technical literature. Section Error! Reference source not found. describes the experience on the planning and design of the building energy system at UDES. The paper finish in section 7 with some concluding remarks.

\section{Building Energy System: Barriers and Opportunities}

A comprehensive analysis of a low-carbon transition of China high rise residential buildings is presented in [4]. There Wang et al. propose some technological solutions (active and passive) for electricity and heat conservation and efficient end-use, as well as a planning path for increasing the renewable energy system integration in high rise buildings. It is interesting to see the increasing importance of heat pumps and shallow geothermal technology for achieving higher levels of efficiency in high rise buildings. The opportunities are listed under the light of the three major trends of this century: decarbonization, decentralization, and digitalization. Besides, Wang et al. highlight the role of the policy system to improve the technical codes and evaluation standards for the acceptance and maintenance of low carbon high rise buildings is a key factor in achieving the transition because of the gained extensibility.

Consequently, Durvey et al. [6] present the six types of barriers that affect building energy-saving technologies, and as one of the more important appear the Governmental/ Political/ Regulatory barrier. The other five in decreasing order of importance are: Financial/ Economic, Cultural/ Social/ Behavioral, Professional/ Technical, Technological, and Market barriers. According to Durvey et al., more research on the topic is done in Europe, which explains why the market and technological barriers are the least relevant barriers. Putting 
this aside, maybe the least evident and most recurrent barrier that appears across all technical literature is related to the Professional/ Technical type of barrier [7]. This may include the lack of a technical standard for the construction process of a green building, besides the lack of training available for new sustainable techniques and technologies; and the lack of skilled and specialized labor [7].

In fact, the list of measures for building energy efficiency by itself might have some implementation barriers, as explained in [8]. There, Gonzales-Caceres et al. identify that "just enough" implementations are an essential barrier since this yield to unattractive results due to ambiguous definitions or flexible barriers that do not exploit the benefits of energy efficiency in buildings properly. In general, according to Lu et al. in [9], the major drivers for sustainable building projects are energy and water efficiency, as well as company image and reputation. There the importance of green labeling and information dissemination is made evident.

Most common drivers and incentives, of course, are the financial and market-based incentives [9] [10], but in termsof the barriers the importance changes according to the participant (Contractor, Consultant, Designer and Manufacturer) [11]. For example, for a consultant point of view, the lack of standard seems to be not significant, while for a contractor, it is essential. In turn, for the contractor itself, the platform to publicize and demo new technologies is irrelevant, which turns out to be a very crucial factor for the designer. Interestingly enough, the designer and manufacturer see the lack of qualified professionals as an important barrier, while for the consultant this is not the case. This difference in the perception of barriers as been detected also in [12], this time taking as actors the governmental authorities, building developers, architects, engineers, and PV manufacturers. These similarities may indicate that results in studies as the one presented in [6], might be useful to analyze the feasibility of a sustainable building project in developing countries. Nonetheless, further studies must be done to delimitate the scope of this kind of adaptations.

In developing countries, the most important driver is a mix of on-site generation with economic benefits. Besides, the green mark and avoidance of $\mathrm{CO} 2$ are increasing their relevance in this context. In contrast, the long-term payback period, high upfront costs are considered as substantial barriers to sustainable building implementations [12]. Now, it worth noticing that in developing countries, the incompetence of project managers and the low implementation of sustainable practices are important barriers [13]. Finally, the study presented in [14] again shows the fundamental similarities between developing and developed countries, in what respect to sustainable building implementations. There, Darko et al. presents the government as the main barrier because of the influence of this actor in the regulations and standards required for a sustainable building industry.

\section{Experiences and Lessons Learned}

The "Universidad de Santander" (UDES) is a private nonprofit higher education institution from Colombia. Its main campus is in Bucaramanga, the fifth greatest Colombian city, but it has campuses all over the north-east region of the country. The compromise with a sustainable campus has led UDES to be the more sustainable campus on Bucaramanga. As for today, UDES is on the top 20 of the more sustainable universities in Latin-America. The vision of a sustainable campus started by protecting 30 hectares of the surrounding forest, and it has been since then a critical trait in the UDES alumni. With actions as policy on energy and water efficiency and waste management, it was only a matter of time the 
integration of the renewable energy inside the campus; although, it was not a smooth ride.

Two are the key factors that contributed to the final design of the solar PV (photovoltaic) plant on the roof of one of the main campus buildings (see Fig. 1): (1) Statal regulatory incentives; and, (2) Energy efficiency benefits awareness. On the regulatory aspect, Colombia has been up to date in comparison with other Latin-American countries. For example, in 2001 a law was signed to promote energy efficiency and renewable energy sources; however, the incentives were proposed until 2014 and defined in 2018 by the national electricity and gas sector regulator. Moreover, there are some tax discounts on the importation fees, VAT, and on the depreciation of the equity related to renewable energy generation, which results in the reduction of up to a $30 \%$ with respect to the original investment. With this regulatory framework ready and thanks to the decline of the PV systems prices, nowadays, in Colombia a power plant like the one installed at UDES can recover the investment from 4 to 6 years.

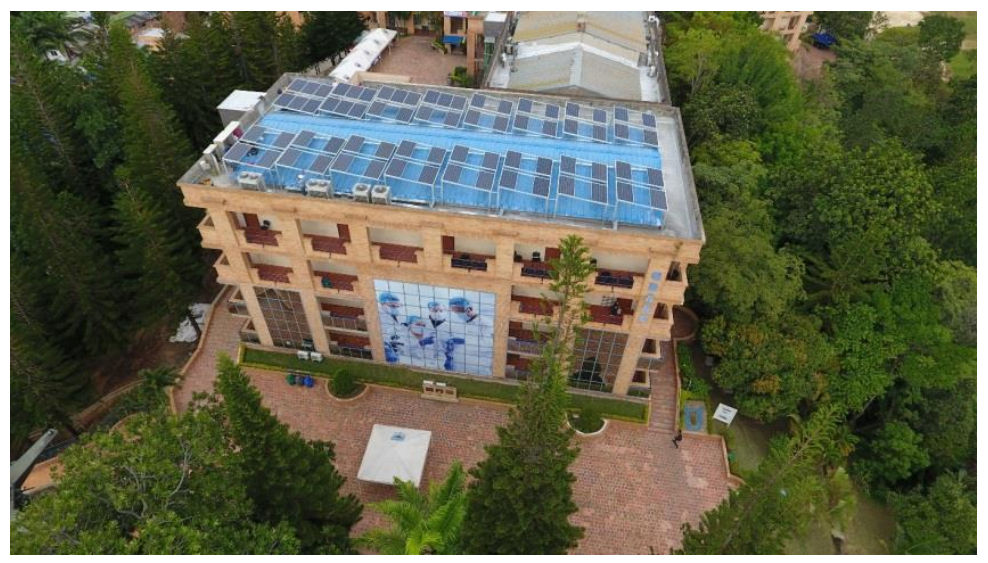

Figure 1. Universidad de Santander (UDES) solar (photovoltaic) power plant.

On the benefits awareness aspect, the role Colombian government has also been active, with lots of divulgation done across productive sectors and with the help of local universities. The idea with this kind of approach was to generate a collaborative workforce that eventually would generate a culture of energy efficiency. However, in several sectors due to lack of financial support, all those efforts did not work. Besides, the good practices and regulations for building energy efficiency has found a major barrier in the lack of standard and measurement of energy efficiency.

Under this harsh scenario, the opportunity that makes feasible the solar power plant begins with a change of legacy conditioned air (AC) system on the main campus. The investment was made thinking not only in the short-term benefits but also seeking a future implementation of renewable energies. Thus, the decision making took the energy efficiency of the system as a priority and made very attractive the implementation of a solar power plant. Thanks to the change in de AC system technology, the resulting power plant capacity can supply near $70 \%$ of the building's demand (see Fig. 2), just $10 \%$ less than the estimative presented at the beginning of the project. 


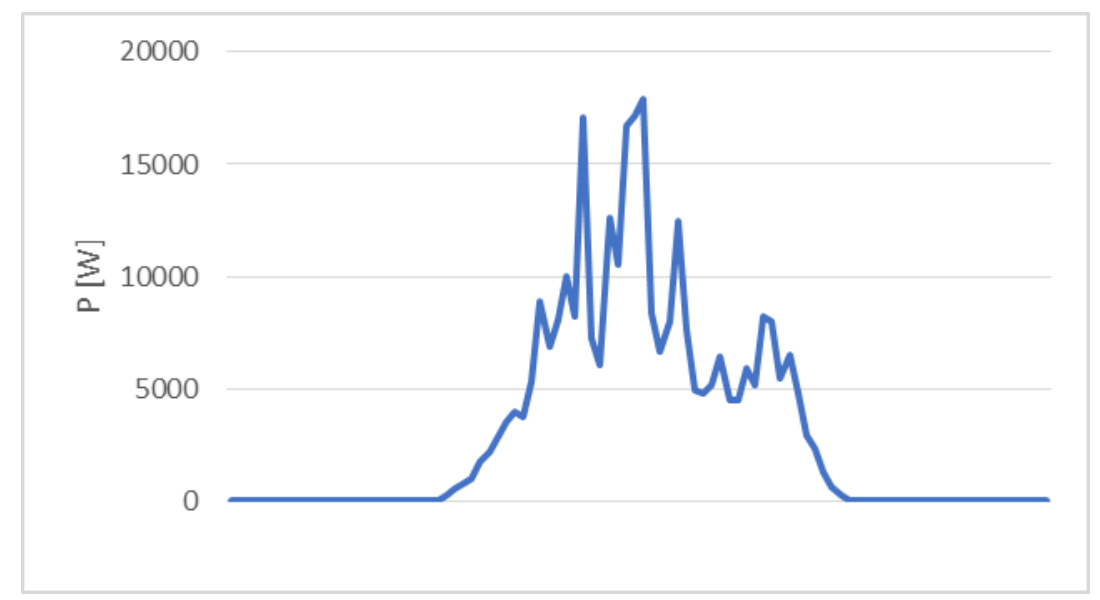

(a)

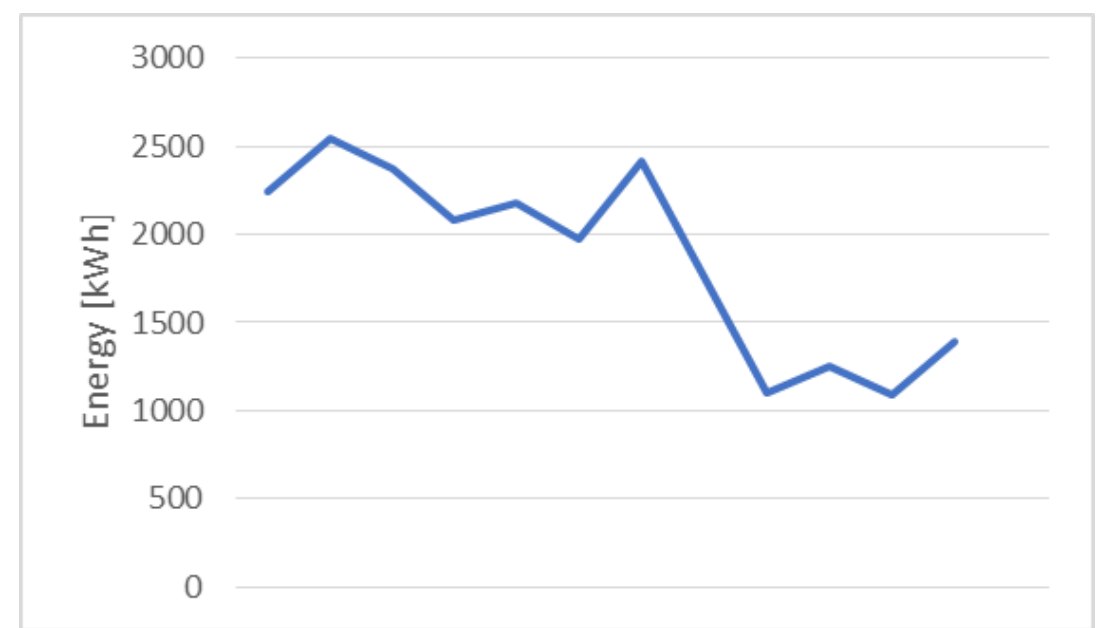

(b)

Figure 2. (a) Daily generation for August $23 / 2020$ of the PV power plant at UDES main Campus. (b) Monthly generation for 2019 (August/2019 - July/2020). Due to the start of a small raining season, energy delivered has been halved.

In total, the UDES has planned $100 \mathrm{~kW}$ of installed capacity for their main campus, and is integrating PV generation in all campuses across the country, thus showing that Colombia is through a PV spring leveraged by the current regulation.

The decision for the installation of new PV capacity on other campuses, and the extension of the UDES main campus capacity came due to the possibility to inject the energy surplus back to the grid. The regulation has two levels of incentives: first, if the injected energy is less than the monthly demand, and energy credit is used to recognize the renewable generation; If the monthly energy generated is greater than the monthly demand, all the surplus is paid according to an adjusted average of the spot price of the wholesale electricity market. This adjusted average then is further changed to take into account the system losses that are avoided thanks to the energy exportation. Without this latter incentive, the aggressive expansion of the solar generation would not have been possible; hence, the timing of each step was crucial to convince the stakeholders of the project to invest. In conclusion, the experience at UDES shows that the drivers and barriers identified in the technical literature are indeed very helpful, since most of them are general enough to be applicable in several contexts. In the case of UDES, the barriers and drivers 
presented in [12] are in accordance with the resulting experience.

\section{Concluding Remark}

A condensed view of the opportunities and barriers that face energy building design and planning was presented along with the experience behind the implementation of a solar power plant in the main campus of the Universidad de Santander. In general, the implementation has been a success that now is being replied in other UDES' campuses, and the decision taking involved highlighted the importance of a proper energy efficiency policy and electrical regulation analysis.

\section{References}

1. X. Cao, X. Dai, and J. Liu, "Building energy-consumption status worldwide and the stateof- the-art technologies for zero-energy buildings during the past decade," Energy Build., vol. 128, pp. 198-213, Sep. 2016, doi: 10.1016/j.enbuild.2016.06.089.

2. S. B. Sadineni, S. Madala, and R. F. Boehm, "Passive building energy savings: A review of building envelope components," Renew. Sustain. Energy Rev., vol. 15, no. 8, pp. 36173631, Oct. 2011, doi: 10.1016/j.rser.2011.07.014.

3. N. M. P. Bocken, S. W. Short, P. Rana, and S. Evans, "A literature and practice review to develop sustainable business model archetypes," J. Clean. Prod., vol. 65, pp. 42-56, Feb. 2014, doi: 10.1016/j.jclepro.2013.11.039.

4. Y. Wang, D. Mauree, Q. Sun, H. Lin, J. L. Scartezzini, and R. Wennersten, "A review of approaches to low-carbon transition of high-rise residential buildings in China," Renew. Sustain. Energy Rev., vol. 131, p. 109990, Oct. 2020, doi: 10.1016/j.rser.2020.109990.

5. S. AlSanad, "Awareness, Drivers, Actions, and Barriers of Sustainable Construction in Kuwait," Procedia Eng., vol. 118, pp. 969-983, Jan. 2015, doi: 10.1016/j.proeng.2015.08.538.

6. T. M. Cristino, F. A. Lotufo, B. Delinchant, F. Wurtz, and A. Faria Neto, "A comprehensive review of obstacles and drivers to building energy-saving technologies and their association with research themes, types of buildings, and geographic regions," Renew. Sustain. Energy Rev., vol. 135, p. 110191, Jan. 2021, doi: 10.1016/j.rser.2020.110191.

7. N. Kasai and C. J. C. Jabbour, "Barriers to green buildings at two Brazilian Engineering Schools," Int. J. Sustain. Built Environ., vol. 3, no. 1, pp. 87-95, Jun. 2014, doi: 10.1016/j.ijsbe.2014.05.004.

8. Gonzalez-Caceres, A. K. Lassen, and T. R. Nielsen, "Barriers and challenges of the recommendation list of measures under the EPBD scheme: A critical review," Energy Build., vol. 223, p. 110065, Sep. 2020, doi: 10.1016/j.enbuild.2020.110065.

9. Darko, A. P. C. Chan, E. E. Ameyaw, B.-J. He, and A. O. Olanipekun, "Examining issues influencing green building technologies adoption: The United States green building experts' perspectives," Energy Build., vol. 144, pp. 320-332, Jun. 2017, doi: 10.1016/j.enbuild.2017.03.060.

10.W. Shen, W. Tang, A. Siripanan, Z. Lei, C. F. Duffield, and F. K. P. Hui, "Understanding the Green Technical Capabilities and Barriers to Green Buildings in Developing Countries: A Case Study of Thailand," Sustainability, vol. 10, no. 10, p. 3585, Oct. 2018, doi: $10.3390 /$ su10103585.

11.W. Deng, T. Yang, L. Tang, and Y.-T. Tang, "Barriers and policy recommendations for developing green buildings from local government perspective: a case study of Ningbo China," Intell. Build. Int., vol. 10, no. 2, pp. 61-77, Apr. 2018, doi: 
10.1080/17508975.2016.1248342.

12.Y. Lu, R. Chang, V. Shabunko, and A. T. Lay Yee, "The implementation of building integrated photovoltaics in Singapore: drivers versus barriers," Energy, vol. 168, pp. 400-408, Feb. 2019, doi: 10.1016/j.energy.2018.11.099.

13.H. Pham, S.-Y. Kim, and T.-V. Luu, "Managerial perceptions on barriers to sustainable construction in developing countries: Vietnam case," Environ. Dev. Sustain., Feb. 2019, doi: 10.1007/s10668-019-00331-6.

14.Darko, A. P. C. Chan, Y. Yang, M. Shan, B.-J. He, and Z. Gou, "Influences of barriers, drivers, and promotion strategies on green building technologies adoption in developing countries: The Ghanaian case," J. Clean. Prod., vol. 200, pp. 687-703, Nov. 2018, doi: 10.1016/j.jclepro.2018.07.318. 